\title{
Developing a Framework for Classroom Lesson Delivery to Improve English Teachers' Performance in the Foundation Year Programme at a Saudi University
}

\author{
Saeed J. Aburizaizah ${ }^{1}$ \\ ${ }^{1}$ English Language Institute, King Abdulaziz University, Jeddah, Saudi Arabia \\ Correspondence: Saeed J. Aburizaizah, English Language Institute, King Abdulaziz Univeristy, P.O. Box 80200, \\ Zip 21589, Jeddah, Saudi Arabia. Tel: 96-655-552-1709. E-mail: saburizaizah@kau.edu.sa
}

Received: October 8, 2013 Accepted: October 28, 2013 Online Published: December 5, 2013

doi:10.5539/elt.v7n1p1 URL: http://dx.doi.org/10.5539/elt.v7n1p1

\begin{abstract}
The current English programme provided to foundation year students at King Abdulaziz University is failing to equip learners with the desired level of English language. This paper assesses the teaching materials and proposes a teaching framework to improve teachers' lesson delivery. The framework was designed to overcome some of the shortfalls in the mandatory course book series (Headway Plus). The framework adopted Kumaravadivelu's (2010) principles for lesson delivery: diagnosis, treatment and assessment, and advocates the development of cognitive ability, encourages collaborative learning, problem solving, emphasizes process rather than product, communication skills, and self-inquiry. Fifteen English teachers participated in a pilot study by implementing the new lesson delivery framework over a 14-week course. A peer observation strategy was used to help the teachers reflect on their teaching methods and improve the quality of their teaching. Also, during the last two weeks of the course the head of the English unit and an external observer conducted observations to monitor and assess teachers' development. The findings of the study revealed the new framework helped teachers improve their lesson delivery and encouraged them to use new teaching techniques such as problem solving and a student-centred approach. However, the results also indicated there was a need for teacher training courses to help teachers understand the principles behind the different teaching methodology. In addition, a cultural factor was found to be influential, as some teachers were reserved about criticizing other teachers' performance.
\end{abstract}

Keywords: youndation year, headway plus, performance evaluation, development, teachers

\section{Introduction}

\subsection{Research Context}

The teaching of English as a second language in a non-English speaking country always gives rise to difficulties in the presentation of the material to be learned, the choice of teaching methodology, and in measuring outcomes, as well as in how to teach in a way that is socially acceptable for the country in question (Holliday, 1997). At the King Abdulaziz University (KAU) in Saudi Arabia (SA), the English Language Institute (ELI) is responsible for teaching four levels of English as part of the foundation year. The ELI programme at KAU has developed over time without a needs assessment, without any consideration of appropriate teaching methodology or methods of assessment, with no clearly defined objectives or academic process, and no consideration of socio-cultural appropriateness. Although the instructors on the ELI programme at KAU are English speakers, they are not necessarily native speakers of English, may not have been educated in the use of various teaching methods, and may not understand the principles of teaching adults such as university students. The purpose of this study was to assess and test a framework to improve the teaching of English classes for second language learners.

\subsection{The Teaching Material}

The ELI programme has been using a new version of Headway Plus (Soars \& Soars, 2012) for three years. The textbooks were modified to be more appropriate for a Middle Eastern context and to meet the specific needs of students in Saudi Arabia. The changes were mainly superficial (names, types of music etc.); however, and did not meet the needs of students in SA. In this textbook, the English language is introduced, with a focus on accuracy and controlled practice. It addresses everyday issues and is considered appropriate for both males and females 
(Waters, 2012). Topics in the Headway Plus books cover everyday life issues such as shopping, families, friends, the way I live etc., and most of the written and spoken materials are not 'authentic.' The text concentrates on speaking, listening, reading, writing, vocabulary, and grammar using an integrated approach; however, a greater emphasis is placed on grammar (Sung, 2013). The Headway Plus textbook series is an example of the Present, Practice, Production (PPP) approach to teaching (Case, 2008; Waters, 2012). The textbooks provide a great deal of input and practice; however, students rarely engage in the production stage (Case, 2008). The text does not take into consideration the unique socio-cultural context of SA; however, for political reasons it is not possible to change texts, as the ELI is seeking to meet the standards of international accreditation and this curriculum meets those standards.

Headway Plus purports to focus on improving listening, speaking, reading, and writing skills in addition to learning vocabulary and grammar in an integrated approach. However, as Waters (2012) found Headway Plus puts the emphasis on grammar and about half of each unit focuses on skill and drill to reinforce the target grammar forms (Waters, 2012). In theory, the Headway Plus series was introduced to improve communication skills; however, in classroom practices there is a great deal of variation. In theory, the course books provide a copious amount of input and practice, while production of the language to be learned is the weakest aspect of the books. Learners rarely use the target language in the final stage or in the free production stage of the lesson (Case, 2008).

\subsection{Rationale for Introducing Alternative Classroom Teaching Framework}

One of the points made in the literature is the need for learning materials to reflect the broader context and socio-cultural background of learners; however, this is not the case with the Headway Plus materials used at tertiary education level in Saudi Arabia. The ELI is seeking international accreditation, and in order to meet the curriculum standards of the accrediting organization and avoid criticism, the institute adopted an internationally recognized series regardless of the actual needs of learners and the learning context.

ELI students need to learn English and develop English language skills to help them pursue their subject courses successfully (Aburizaziah, 2010). Students entering the schools of engineering, science and medicine at KAU need a wide range of language skills and proficiency in order to read academic books, listen to academic lectures and write essays. Learners are expected to develop cognitive ability, confidence, affective engagement, and self-reflection as a part of their English instruction (Aburizaizah, 2010; Ellis, 2003; Tomlinson, 2001). In order to accomplish these goals, it was necessary to develop a new lesson delivery system as an alternative to Headway Plus to overcome the current constraints of the Headway Plus system.

Every teaching method has advantages and disadvantages and there is no one teaching method suitable for all contexts and all students; however, this study was not concerned with selecting one teaching method over another. Harmer (2003) stated, "the problem is not with the methodology itself, nor with the ideas it generates, but rather with how they are amended and adopted to fit the needs of the students who come into contact with them" (p.192). What was important was to begin to develop a new teaching framework taking into consideration factors that would help ELI teachers utilize their teaching method, have a degree of freedom in how instruction delivered, extend the teacher's role to include that of a researcher within the classroom, and improve their performance as English instructors.

\section{Frameworks for English Language Learning}

The study referred to in this article was an attempt to develop a framework for teaching and methodological concepts that could be used in the teaching of English as a second language. This was accomplished by paying attention to teaching approach, goals, and measurable outcomes. It was necessary for the ELI to consider a more systematic type of lesson development and to reassess the role of teachers in the classroom and students' engagement in the lessons. It was also necessary to develop the framework within the limits set by the current Headway Plus curriculum. The objective was to develop a framework capable of enabling language learning through cognitive and metacognitive techniques, focusing on what is learned, how it is learned and how goals are achieved. "It's not what pupils learn that makes the difference, it's how they learn" (Lin \& Mackay, 2004, p. 4).

To design a systematic teaching framework, three practical "post-method" principles suggested by Kumaravadivelu (2001) were adopted. Task-based language teaching (TBLT) principles and practices introduced by Nunan (2004) were also incorporated into the design of the framework providing in-class practice activities. The framework was infused with cognitive skill strategies with the aim of creating purposeful learning. The design of the framework is described in the following section. 


\subsection{Conceptualising Post-Method in the Classroom}

Many teachers appreciate the formality and structure offered by teaching methods, since they offer a fixed system for classroom instruction and help teachers make decisions regarding, for instance, what to teach, when to teach, and whom to teach. Unfortunately, teachers find the use of a specific method offers little opportunity for individual interpretation (Richards \& Rogers, 2000). Teachers often have to change or adapt their teaching style to make it conform to the method. A specific teaching method does not always allow for differences in the social, political, and historical backgrounds of participants (Kumaravadivelu, 2001). Another problem with teaching methods is the difference in the fundamental philosophy of the method. Teachers are typically asked to use the teaching method specified by a curriculum without having the opportunity to assess which method would work best with which students (Brown, 2002). Holliday (1997) noted that teachers returning from training programmes are not able to implement what they have learned owing to conflicts with real-life teaching situations. There is no one teaching method that will be successful in every context and for every student. It is necessary for teachers to have the ability be flexible, think on their feet, adapt, and tailor their teaching to each unique class of students (Ur, 2004).

All methods have a limited lifespan and there has never been one method suited to every situation. In the 1990s, the focus was transferred to the development of a 'post-method condition' underlying everything happening in the classroom (Kumaravadivelu, 2001). Post-method is characterized as a general framework where teachers have the freedom to utilize any teaching context and any teaching material appropriate for the task to be learned. Post-method is based on the teacher's identification and understanding of the local context and continues as an ongoing monitoring process in the classroom. However, it requires teachers to have a high level of awareness, training and motivation to change their teaching style.

Post-method consists of three sequential stages, which Brown (2002) referred to as diagnosis, treatment and assessment. These three stages would be very effective for ELI programmes, since the stages transcend the limitations imposed by the current curriculum. Post-method also opens up new opportunities for teachers to work with a diversity of learners' needs. Diagnosis seeks to raise critical awareness and treatment is based on experimentation. Teachers theorize about their practice and then practise what they have theorized about. Teachers need to use their experience and knowledge. Brown (2002) noted it is also necessary to reassess or reconsider the relationship between their theories. This enables teachers in the classroom to diagnose the needs of students, treat students with successful pedagogical techniques, and assess the outcomes of the treatment (Brown, 2002). Teachers need to be aware of learning needs, wants and situations with less of a focus on curriculum materials, techniques and linguistic analysis. In other words, there is more concentration on what goes on inside the classroom (Kumaravadivelu, 2003; Tudor, 2001). Assessment is based on an evaluation of the context of linguistic and socio-cultural knowledge in addition to the linguistic needs of the students (Kumaravadivelu, 2006; Brown, 2002). However, to conceptualize these pedagogical ideas, teachers need to be able to subdivide learning units to transform them into useful classroom lessons that are easy to follow. An operational system, based on what is to be learned in a particular context is necessary. In order to develop lessons based on the post-modern framework of diagnosis, treatment, and assessment (Kumaravadivelu, 2001), the task-based language teaching (TBLT) framework was selected as a way of developing the lessons.

\subsection{Particular Teaching Units}

The three principles: diagnosis, treatment, and assessment (Kumaravadivelu, 2001; Nunan, 2004; Brown, 1995) were thus put into practice using a TBLT framework (Kumaravadivelu, 2001). TBLT encourages collaborative learning, problem solving, an emphasis on process rather than product, communication skills, and self-inquiry (Ellis, 2003, Nunan, 2004; D. Willis \& J. Willis, 2007). The TBLT method creates learner-centred rather than teacher-centred classrooms. It was necessary to develop a practical method to help teachers process the delivery of their lessons, develop a teaching model, and as a way of evaluating teacher performance. This would emphasize teacher creativity, flexibility, meeting students' learning needs, and the need for reflection It would also be necessary for the methodology to function within the confines of the Headway Plus curriculum.

Classroom research into how TBLT is implemented or how meaning is endorsed is limited. Nunan (2004) and Wills and Willis (2007) introduced a common framework for TBLT; however, there is a gap between pedagogical policy and classroom practice. The TBLT cycle can be rigid if teachers treat TBLT as routine or if teachers are not clear on how to use the framework in a particular context. ELI at KAU needed to develop an in-class framework to help teachers process the delivery of a lesson so it can be used to develop a model of teaching and assess teachers' performance. The framework design also needed to work with the curriculum objectives of Headway Plus. The teaching framework should encourage student engagement and encourage 
teachers to function in the role of facilitators. The framework needs to foster the development of students' cognitive skills in order to result in purposeful learning. It was essential the framework allow teachers to be creative and flexible in attempting to meet learners' needs.

\subsection{The Framework}

The framework could be described as a semi-supervised teaching framework. It included specific classroom activities ELI teachers are expected to complete. It was important to establish clear criteria for teachers to follow and then to assess their performance according to these criteria. The teachers participating in this study did not have an opportunity to attend a training course on the teaching methodology, as training is not an activity KAU is prepared to invest in. However, the teachers did understand what was expected of them and that they needed to be prepared to use the framework for each class. The teachers were also expected to use the framework within the Headway Plus curriculum. It was important for the students in the classes being taught by the teachers participating in this study not be at a disadvantage compared to students in classes with teachers who were not using the framework. The framework was also sequential and flexible enough to include a variety of classroom practices.

The framework consisted of four parts: clear purpose, metacognition, mediation and connecting learning. In the first phase of lesson delivery the teachers were supposed to explain the purpose of the lesson and to raise learners' awareness, then explain the systematic development of the lesson. The treatment or second stage is longer and is intended as a time when learners interact with the task creatively and when the teacher can challenge and facilitate the students' thinking and learning. During this stage, teachers encourage learners to discuss, describe, and articulate their thinking while the teachers theorize from practice and practice what they have been theorizing about. Teachers encourage student independence and intervene when needed. The last phase of the lesson is intended for teachers to assess learners' outcomes, encourage them to reflect on their learning, and to connect the task with a real-life context. Table 1 illustrates the framework developed to improve English teaching and learning at KAU. The framework had a dual purpose, and was designed for both classroom instruction delivery and teacher observation.

Table 1. Teaching framework developed for study

\begin{tabular}{llll}
\hline Diagnosis & Treatment & & Assessment \\
\hline Clear purpose & Metacognition $\longleftrightarrow$ & Mediation & Connecting Learning \\
\hline Clear goal & Analytical perception & Learner-centred & Self-reflection \\
Clear perception & Problem solving & Teacher facilitation & Authentic context \\
Systematic development & Debriefing discussions & Inspire independence & Transfer \\
\hline
\end{tabular}

As shown in Table 1, the three main lesson stages suggested by Kumaravadivelu (2001) was divided into four practical classroom activities.

\section{Methods}

A Teacher Observation Form (TOF) (Appendix A) was developed using the framework established for the study. The framework was structured into an observation form based on the principles of diagnosis, treatment and assessment, and included the following areas: planning, sequencing, instructions/explanations, motivation/stimulation, time management, white board/visuals, space management, teacher/student contact, student practice and summary/reflection. Each area was assessed on a five-point Likert-type scale that included the following options: Outstanding, Above Average, Satisfactory, Needs Improvement and Unsatisfactory. Each area contained a number of areas for observers to monitor when evaluating a teacher, for example: sequencing, objectives, warm-up, presentation, practice, production. The Teacher Observation Form (TOF) also asked for an evaluation of the instructor's English skills and had a place for written comments by the evaluator.

The TOF form was tested using a group of 15 KAU ELI teachers over the course of a 14-week semester. Teachers used the TOF form as a guideline for classroom practice and as a protocol to be evaluated by peer teachers and the head of the ELI unit. The ELI teachers observed and were observed by their peers. Teachers took turns observing and discussing teaching techniques and approaches, exchanging beliefs, ideas and techniques, and sharing ideas about how to improve their teaching. During weeks 12 and 13 of the semester, the head of the ELI along with an external evaluator conducted pre- and post-observations of each teacher. The 
purpose was to evaluate each teacher's performance and make suggestions as to how they could develop their teaching skills. The objective was not only to help the teachers but also to evaluate the TOF for future use. The data for each individual teacher were analysed based on the findings of the observations made by other teachers and the department head. The analysis also assessed how well the TOF addressed the components of the post-method and TBLT framework. The objective was to evaluate not only the teachers and their progress in adapting to the framework but also the value of the TOF as a tool for future use by the ELI department. Teacher evaluations were presented in an aggregated format with no specification as to whether the evaluator was the department head or another teacher.

\subsection{Diagnosis}

Based on the framework developed for assisting and evaluating ELI teachers, the TOF was used during each observation to collect data on the teachers' implementation of the framework. As mentioned above, teachers using the framework were expected to raise students' awareness and explain the lesson goals to them in the diagnosis stage or at the beginning of the lesson (Tomlinson, 2001). In a lesson it is important for learners to know why they are doing a task, what strategies are needed, and how learning the material will benefit them. The peer observation reports indicated this concept of making sure the students clearly understood what they were to learn, why they were to learn it and how they were going to learn it was not clear to most of the teachers nor was there any evidence of it in their teaching. Peer observation comments indicated the teachers understood this requirement as meaning simply that they should write the lesson goals on the board. Observer A noted, "the lesson objectives were clearly written on the board". Observer B stated, "objectives of the lesson were written on the left side of the board. The date and unit were on the right". Based on the peer comments made during their observations, it appeared only one of the fifteen teachers was aware of the first stage requirement, as he noted to a colleague, "major ideas of the lesson were clearly defined and communicated. The teacher needs to state the objectives and make the students more aware of the objectives to be achieved by the end of the lesson". In this introductory part of the lesson students should be told what is to be learned, how this will be done, and how it will be assessed to ensure learning did in fact take place. If students are not told what they are cognitively to pay attention to, they will not know where they should direct their attention.

Observations conducted by the head of the ELI at the end of the 14-week period found most of the teachers were writing the lesson objectives on the board and then reading them out verbally to the students. This improvement in lesson delivery could be attributed to the discussions among the teachers themselves, especially after the observation sessions (Lightbown \& Spada, 2006). Unfortunately, at the end of the 14-week period when the head of the ELI conducted his observation, the teachers were still reading out the lesson objectives without explaining to the learners why or how the lesson was important to their English language learning. The students knew what was to be learned but did not understand why or how. The teachers raised the learners' awareness about the topic and used any strategy to get them motivated for the lesson, rather than thinking about which strategy might work best with a particular topic. For example, Teacher $\mathbf{C}$ wrote on the board and stated aloud, "I am going to teach comparative and superlative forms". Teacher D stated, "Today we are going to continue talking about conditional clauses and 'if' with the past form". This type of introduction to a lesson was too short, did not explain to the learners the purpose of the lesson, did not relate it to their prior learning, and did not explain why the lesson was important to their English studies. These short introductions also did not discuss the development of the lesson or how learning would occur. In the example of the teaching of comparative and superlative forms, the teacher might have started the lesson by explaining what the comparative form is and the importance of comparatives, and how the comparative uses an adjective or adverb to indicate more/less, greater than/less than. The teachers should have explained the superlative is an adjective or adverb indicating that something or someone is outstanding, superior, or absolutely the greatest of all. He could then have introduced the learners to forms using 'more than' or 'most', asking them to think of three or four examples of when it would be appropriate to use these forms. These examples could have been written on the board and shared with the class with a discussion of why each was or was not comparative or superlative. Students and teachers could be creative and think critically about the example and determine whether or not it was being used appropriately (Ellis, 2009). Without this type of feedback, the teacher has no idea whether or not his presentation of the material has been effective. With this feedback from students it would be possible for the teacher to know what had or had not been learned and to think of other ways the material might be taught if necessary (Gray, 2010). One of the important areas in the diagnosis section of a lesson is identifying learners' weaknesses; without feedback from students, teachers will have no idea what these are. 


\subsection{Treatment}

The treatment stage is a key part of the lesson and entails the use of a variety of learning strategies, including: discussion, describing, skimming, putting ideas together, reflection etc. Teachers play an important role in this stage as facilitators of student learning. Teachers' help students develop a deeper understanding of the topic, learn to be more critical, use higher order thinking skills, and become independent learners. This stage involves problem solving tasks, summary writing, comments on pictures, giving presentations, listening to the main idea, describing something, etc.

The peer observation reports and the accountability observation sessions demonstrated this stage was not delivered appropriately by most of the 15 teachers. The problem common to all 15 teachers involved the amount of class time they took up talking in front of the class. This portion of the lesson was purely teacher-centred and the teachers dominated the classroom discussion. The students were simply passive learners and not active participants in the learning process. The teachers strictly followed the course book activities and the students were either not engaged or only barely engaged in the lesson, discussion or tasks to develop their analytical perception. It was noticeable the teachers were trying to follow the pacing guide precisely and to cover all the course book activities within the class time. It was apparent to the observers that this greatly affected the quality of lesson delivery.

Only a few teachers implemented or used group or pair work in the classes. Observer B stated, "The teachers ensured that students work in pairs or groups" and observer C noted, "He grouped them and provided interesting extra relevant materials". However, the observation sessions conducted by the head of the ELI and the external observer revealed most of the group or pair work activities were ineffective. They consisted simply of working on workbook activities and provided little extra help for the students. There was no real discussion or positive communication between the learners in the groups or those in pairs. The observers noted that even when students were working in pairs or groups, they were just chatting in Arabic or waiting for the other students to complete the workbook tasks. The teachers' interventions did not encourage positive discussions or the students communicating in English and the teachers simply allowed the students to work together using their native language rather than English. Sometimes teachers did not give students, particularly weaker students, sufficient time to express themselves and it was interesting that the peer observers also noticed this among their colleagues. Observer E commented, "Students were not given equal chances to participate [in class];" however, some of the teachers allowed too much time for some of the activities. Observer F commented, "Students spent a lot of time in pair groups trying to put into practice what the teacher was trying to teach."

\subsection{Assessment}

In the assessment stage, learners should be given the opportunity to reflect on what they have learned and discuss or comment on the process of their learning. They need to internalize what has been learned, connect this with what has been learned previously, and relate what they have learned to tasks in the curriculum, and to other tasks outside the classroom in a real-life context (Ellis, 2009; Gray, 2010). Connecting and relating learning will make the learning more purposeful and will positively affect learners' intrinsic motivation, as well as ensuring that learning can be recalled in the future (Lightbown \& Spada 2006). The more ways they have of encoding information the easier it will be to use and retrieve this information.

The peer observation reports indicated all of the teachers and observers understood the requirement of this stage to be simply to summarize the lesson and ask learners questions to probe their understanding and learning. Observer J appraised the teacher's approach, rating him 'Above Average', and commented, "at the end of the class Mr. X asked the students to close their books and then he made them retell what they could remember about the lesson." Observer $\mathrm{H}$ stated, "The teacher summarized the major points at the end of the lesson in order to ensure students' assimilation of what they had been taught: e.g., the students were asked to answer some questions for further reinforcement." The head of the ELI and the external observer's reports supported the findings of the peer observation reports. Most of the teachers being observed were dedicating some time at the end of the class to a summary of major points; however, the time allocated for this stage was in general very short, in some classes less than two minutes. Rather than the teacher doing the summarizing, students need to be asked to make their own summary and report this to the class. At the same time, other students might critically assess the accuracy of the summary in light of what they might have learned. Every student brings a different mindset, background, interest and degree of knowledge to any learning situation and every student will learn something different, retain something different, and be able to recall something different. After all, no two brains are wired in exactly the same way and each and every student will take something different from any learning situation. Having students, rather than the teacher, articulate and summarize what they have learned provides 
another way for all of the students to encode learning in a different way.

\section{Summary}

The teachers at the ELI at KAU appear to have become reliant on curriculum-centred and teacher-centred classrooms. They appear to be willing to allow the Headway Plus (L. Soars \& J. Soars, 2012) curriculum to dictate everything they do in the classroom. The Headway Plus curriculum may not be age appropriate, gender appropriate, or include a sufficient variety of materials for different types of learning styles. The Headway Plus programme is based more on a behaviourist rote-learning skill-and-drill approach to learning, rather than on a constructivist approach, where learners construct their own meaning of what is to be learned. The programme also does not help students to develop autonomy, critical thinking skills, problem solving ability, or to exercise creativity in learning (Swan, 2005). The Headway Plus curriculum does not invite students to become active participants in their own learning; however, it would be possible for teachers to be trained to move beyond the curriculum and adapt the curriculum to make the classroom more learner-centred (Waters, 2009). Teacher training will be needed for them to become competent and successful in implementing the TBLT principles of diagnosis, treatment and assessment. Based on the observation reports, teachers need training and practice in how to promote interaction between students and how to ensure that student interaction takes place in English and not in Arabic (Ellis, 2003).

Well trained, capable teachers are able literally to think on their feet, read the expressions of their students and whether of not they looks puzzled and make changes in their instruction as they go through a lesson (Prabhu, 1992). These teachers take into consideration individual student needs, the requirements of the curriculum, and learn to be reflective about their own teaching (Kumaravadivelu, 2001). Brown (1995) noted, teachers need to be able to diagnose the needs of students, treat individual student needs with a successful pedagogy, and to determine whether or not the lesson materials have been learned. One problem with more learner-centred classrooms in SA may be the reluctance of students to step forward and become active learners and participants in their own education. Their previous role as students in high school has been passive and they may not be accustomed to learning to think or to thinking for themselves, as well as not being intrinsically motivated to learn (Holliday, 1997).

This project sought to develop a framework for the education of ELI students in SA through the development of a TOF for observing teachers in their classrooms and with the aim of improving the quality of instruction. While the qualitative comments were effective in providing information on the 15 teachers, it would also be beneficial to track the numeric data to ensure teachers are improving over the course of a semester. It might be beneficial to revise the TOF to be more precise in measuring what teachers are doing in the classroom; additional items could be added to the TOF to assess whether or not a teaching technique was used and also how effectively it was used. However, the present version of the TOF did provide a great deal of information about what happens in classrooms. It may also be necessary to provide teaching examples for teachers of how they might design their classrooms to be more constructivist and learner-centred while still covering the curriculum selected by the ELI. Teachers may need the opportunity to practise different techniques while students are not present. In all probability, the teachers participating in this study were also educated in teacher centred classrooms and it will take some practice for them to become comfortable with newer methods of teaching. A teacher version of the TOF might also be developed to allow teachers to evaluate their own teaching and learning, and provide a way for evaluators and teachers to discuss further changes in teaching techniques.

While the qualitative data indicated there had been some changes in the teachers' methods, developing additional items for the TOF would provide additional numerical information and allow change to be measured over time. It was evident the participating teachers needed further training in how to be teachers, including learning theory, instructional design, and how to incorporate the curriculum into a newer style of learner-centred teaching. This study was limited to the teachers and evaluators participating in the project, and it should be remembered neither teachers nor evaluators had been trained in how to work in a constructivist classroom. Implementing change is never easy or fast. Monitoring change over time will be necessary to evaluate the effectiveness of this framework and change in teaching. It will also be necessary to determine the effect of changes in instructional methodology on the actual learning of the students, as it will be necessary for the students to master how to learn in student-centred classrooms.

\section{Acknowledgements}

This project was funded by the Deanship of Scientific Research (DSR) King Abdulaziz University, Jeddah, under grant No. 16/126/1433. The author, therefore, acknowledge with thanks DSR technical and financial support. 


\section{References}

Aburizaizah, S. (2010). Evaluation of An English Language Programme for engineers in a Saudi Arabian University: A case study. (Unpublished PhD dissertation). Newcastle University.

Brown, J. (1995). The Elements of Language Curriculum. Boston: Heinle and Heinle.

Case, A. (2008). TEFL net: 15 variations on PPP. Retrieved from http://edition.tefl.net/ideas/teaching/variations-on-ppp

Ellis, R. (2003). Task-based language learning and teaching. Oxford: OUP.

Ellis, R. (2009). Second language acquisition, teacher education and language pedagogy. Language Teaching, 43(2), 182-201. http://dx.doi.org/10.1017/S0261444809990139

Gray, J. (2010). The construction of English: Culture,consumerism and promotion in the ELT global coursebook. Basingstoke: Palgrave Macmillan.

Harmer, J. (2003). Popular culture, methods, and content. ELT, 75(3), 288-294. http://dx.doi.org/10.1093/elt/57.3.288

Holliday, A. (1997). Six Lessons: Cultural Continuity in Communicative Language Teaching. Language Teaching Research, 1(3). http://dx.doi.org/10.1177/136216889700100303

Kumaravadivelu, B. (2001). Toward a Postmethod pedagogy. TESOL Quarterly, 35, 537-560. http://dx.doi.org/10.2307/3588427

Kumaravadivelu, B. (2006). Changing Tracks, Challenging Trends. TESOL Quarterly, 40(1), 59-81. http://dx.doi.org/10.2307/40264511

Lightbown, S. (2006). How languages are learned (3rd ed.). Oxford: OUP.

Lin, M., \& Mackay, A. (2004). Thinking Through Modern Foreign Languages. Cambridge: CUP.

Nunan, D. (2004). Task-based language teaching. Cambridge: Cambridge University Press.

Prabhu, N. S. (1992). The dynamics of the language lesson. TESOL Quarterly, 26(2), 225-241. http://dx.doi.org/10.2307/3587004

Richards, A., \& Rodgers, T. (2001). Approaches And Methods In Language Teaching. Cambridge: Cambridge University Press.

Soars, L., \& Soars, J. (2012). New Headway Plus. Oxford: OUP.

Sung, M. (2013). Language teaching methodology and teacher education: Trends and issues. The Language Teacher, 37(1), 21-24.

Swan, M. (2005). Legislation by hypothesis: The case of task-based instruction. Applied Linguistics, 26(3), 376-401. http://dx.doi.org/10.1093/applin/ami013

Tomlinson, B. (2001). Materials development. In R. Carter, \& D. Nunan (Eds.), Teaching English to speakers of other languages (pp. 66-71). Cambridge: CUP.

Tudor, I. (2001). The Dynamics of the Language Classroom. Cambridge: Cambridge University Press.

Ur, P. (2004). A Course in Language Teaching Practice and Theory. Cambridge: Cambridge University Press.

Waters, A. (2009). Advances in materials design. In M. H. Long, \& C. J. Doughty (Eds.), The handbook of language teaching (pp. 311-326). New York: Wiley-Blackwell.

Waters, A. (2012). Trends and issues in ELT methods and methodology. ELT, 66(4), 440-449. http://dx.doi.org/10.1093/elt/ccs038

Willis, D., \& Willis, J. (2007). Doing task-based teaching. Oxford: OUP.

\section{Copyrights}

Copyright for this article is retained by the author(s), with first publication rights granted to the journal.

This is an open-access article distributed under the terms and conditions of the Creative Commons Attribution license (http://creativecommons.org/licenses/by/3.0/). 